\title{
Release of data following a serious incident in the UK construction industry
}

John Carpenter CEng, FICE, CFIOSH

Consultant, Sale, Cheshire, UK

\begin{abstract}
A fundamental part of the professional engineer's duty is to keep abreast of contemporary information that is relevant to their particular area of work. In an industry where labour input (in its widest sense) predominates, despite all our software and sophisticated construction equipment, this is essential as scope for error is ever present. The nature of the construction industry is such that catastrophic failure, with the potential for multiple fatalities and other concerns, is a plausible scenario. Hence, in order for the forensic engineer to operate, and industry generally to learn from the misfortunes of others, the requisite data from serious incidents must be made available to the industry at large, comprehensively and timeously. As things stand in the UK, it is frequently not so available. This aim, namely to learn, is distinct from apportioning blame. This paper examines why this lack of data exists, touches on the practice in some other countries, and considers what might be done to alleviate the situation.
\end{abstract}

\section{Introduction}

For engineers, the learning process never ends. A fundamental part of the professional engineer's duty is to keep abreast of contemporary information that is relevant to his or her particular area of work. Although some of this requirement relates to new methodologies and materials, some will relate to learning the lessons from past mistakes so that these may be avoided in the future. In an industry where labour input (in its widest sense) predominates, despite all of the software and sophisticated construction equipment, this is essential as scope for error is ever present.

The nature of the construction industry is such that catastrophic failure, with the potential for multiple fatalities and other concerns, is a plausible scenario. This was illustrated in 2012 when a completed steel frame, but incomplete structure, suddenly collapsed, minutes after the workforce of 20 or so had left the site (Construction Enquirer, 2012).

Hence, in order for the forensic engineer to operate, and industry generally to learn from the misfortunes of others, the requisite data from serious incidents must be made available to the industry at large, comprehensively and timeously. As things stand, it is frequently not so available. This aim - that is - to learn, is distinct from apportioning blame, which is the province of others, specifically the courts.

This paper examines why this lack of data exists, touches on the practice in some other countries, and considers what might be done to alleviate the situation in the UK.

\subsection{Serious incidents}

The question arises 'what do we mean by a serious incident?' There is no specific definition and such an approach could be restrictive. However, it was suggested in a Health and Safety Executive (HSE) research report on catastrophic events (HSE, 2011) that it includes events which

n could cause multiple deaths/serious injuries

- affect many workers or any member of the public

- could cause serious disruption of infrastructure and services

- could destroy organisations commercially

- could lead to a public enquiry or demands for new legislation

- are classically 'low probability: high consequence'.

HSE's major incident procedures (HSE, 2014a) state

A major incident is defined as a significant event, which demands a response beyond the routine, resulting from uncontrolled developments in the course of the operation of any establishment or transient work activity.

The event may either cause, or have the potential to cause, either:

multiple serious injuries, cases of ill health (either immediate or delayed), or loss of life, or

- serious disruption or extensive damage to property, inside or outside the establishment

Events which, taken in isolation, may not warrant classification as major incidents, may do so when considered together. 
Significance is determined by the severity of the incident, the degree of public concern and the nature and extent of HSE's previous involvement with the duty holder(s).

Thus these definitions should not restrict consideration to the largest or most devastating events (e.g. Piper Alpha or the Buncefield fire and explosion). The collapse of the steel frame mentioned in Table 1 did not kill or injure anyone, nor did it affect infrastructure (remarkably the frame collapsed almost within its own footprint), but it clearly had the potential to be a major event and should therefore, in the author's view, be included within the above definition. There are other examples which, although small scale in physical terms, are of a potentially repetitive nature and hence derive their relevance from this attribute.

This is a significant point as hitherto 'serious' has been interpreted by some, and specifically HSE, as something much bigger in size or consequence. This is seen from Table 2 and discussed later. This interpretation has had the consequence of reducing the profile of, and attention to, a significant number of these 'lesser' incidents which, nonetheless, have had the potential to increase knowledge of the systemic or specific causes of failure.

\subsection{Inhibitors to information flow}

Following an incident, one or more of the following may occur.

(a) An internal investigation may be undertaken by those parties involved.

(b) A criminal investigation may be instigated, sponsored by HSE (or by the police if individual or corporate manslaughter charges are being contemplated).

(c) A civil case investigation may be put in place, sponsored by insurers, or involving court or expert witnesses.

In case (a) above, it may not be widely known outside the organisations involved that an incident has occurred (although, as will be seen, others industries do have a culture of information dissemination). HSE will only be aware if it is formally reportable under statutory provisions (Riddor) (HMG, 1995) or through local intelligence. Employees may be restricted by their contract of employment from making any statement or may be nervous about becoming involved or attracting liability. Care also has to be taken by the organisations investigating the incident; depending upon the commissioning method, the reports may become disclosable in

\begin{tabular}{lr} 
Type and example & Year \\
\hline Explosions & \\
- Appleby-Frodingham steelworks, Scunthorpe & 1975 \\
- Laporte Industries, Ilford & 1975 \\
- Abbeystead & 1984 \\
- Putney & 1985 \\
- Rutherglen & 1985 \\
- Piper Alpha & 1988 \\
- Corus & 2001 \\
- Buncefield oil depot & 2005 \\
Fire & \\
- HMS Glasgow & 1976 \\
- B\&R Hauliers, Salford & 1982 \\
- Hickson \& Welch, Castleford & 1992 \\
Train crashes & \\
- Southhall & 1997 \\
- Ladbroke Grove & 1999 \\
- Hatfield & 2000 \\
Potters Bar & 2002
\end{tabular}

Table 2. Incidents which have led to the use of section 14

the event of future formal enquiry. This can be a disincentive to investigate and communicate.

In case (b), there tends to be a complete shutdown of communications with the 'wider world' from the moment HSE or the police enter the scene. Care has to be taken by anyone reporting on the case that they are not placing themselves in contempt of court or at risk of a defamation action. This concern usually has the effect of 'locking up' important learning lessons for years. Even after the conclusion of the investigation, if the case does not proceed, the information may never formally appear in the public domain. Table 1 illustrates some examples where information has failed to appear.

The Milford Haven bridge collapse predates the Health and Safety at Work etc. Act (1974) but illustrates how the lack of data is not a new phenomenon (and this particular example contrasts vividly with the action of the Australians following the collapse of the Yarra bridge in 1971, which was to set up a Royal Commission with publically accessible proceedings and report (Royal Commission,
1971

2008

2012

2012
Milford Haven box girder bridge collapse during construction

Gerrards Cross rail tunnel collapse during construction, but in use

Steel building frame collapse, after completion, but before completion of building, Ilford Foundation reinforcement cage collapse prior to concreting, East Anglia

Table 1. UK incidents subject to investigation where no information

has been formally released 
1971). The lessons of this report are still valid today and should be known to all those structural engineers entering the profession).

It is not just the UK which suffers from this paucity of data. The Palau bridge, which collapsed in 1996, is a notable example whereby insurers have failed to allow the release of critical information which would enable the bridge fraternity to learn valuable lessons. Notwithstanding, some have done their best to analyse the failure from the data that are in the public domain, coupled with general engineering expertise (Burgoyne and Scantlebury, 2008).

Of those criminal cases which do, ultimately, go to court there are few occasions where the lessons are specifically disseminated in a format or manner which allows the root causes and lessons (actual or likely) to be conveyed to industry. Ramsgate Ro-Ro terminal walkway collapse in 1994, is an example where information was made available through the joint efforts of Jack Chapman, who sat through the trial as an observer and subsequently published a paper (Chapman, 1998), and indirectly the Construction Industry Research and Information Association, which produced Safety in Ports - Ship-to-Shore Linkspans and Walkways. A Guide to Procurement, Operation and Maintenance (Marks, 1999), taking on board the lessons learnt. However, as can be seen from Table 3, later in the paper, it took 3 years for the trial to conclude, and 5 years before the guide was available. In addition it is noteworthy that there was no specific attempt to formally identify the generic lessons applicable to the construction industry as a whole. Instead the focus was on marine structures.

The third case $(c)$ is perhaps the most common and can run without a parallel criminal investigation, alongside it, or by following it. It too tends to result in silence, stemming in this situation initially from a general duty of care on the part of the forensic experts involved, and finally, contractual confidentiality agreements, preventing the release of the relevant data. Most civil action cases are settled out of court, including, as part of the settlement agreement, such a confidentiality clause, thus ensuring the lack of information prevails.

It is a moot point whether, in the case of safety-related causes of failure, withholding details of 'what went wrong' in connection with a significant failure is in contravention of an engineer's wider duty of care, or of legislative responsibility to make known significant risks. As far as the author knows this has never been tested, but it brings into focus the complex and often frustrating situation in which engineers find themselves. The author has been at meetings where a specific failure was being discussed, with some meeting attendees knowing the root causes, but, because of their involvement, unable to take part in the discussion or impart any knowledge.

Most players in civil cases (expert witnesses, brokers, lawyers) do not own the critical information; they act on behalf of and under the instruction of others. It will require positive action to change this situation so as to allow safety-related information to be released in a controlled, no-blame manner.

There has been some, limited, discussion around the feasibility of

- incorporating into the code of conduct of professional institutions a requirement for their members, who act as expert witnesses, to divulge information which would have a public benefit, or

- limiting the period of confidentiality to say 10 years, after which those involved would be able to inform others.

\subsubsection{Building control}

Many of the incidents, or situations which could have become incidents, and from which causal information would be beneficial to industry, relate to buildings. As such, building controllers (either local authority, approved inspectors, or, in Scotland, certifiers of design), are in a position to know of and disseminate such data in a manner that would not identify the parties concerned. Unfortunately at present there is no incentive for this to occur and in England, the sometimes 'commercial tension' between local authority building control and approved inspectors, militates against such a path.

\section{Legal considerations}

In the context of matters relating to failures and the like, and where a matter is legally 'live', those involved in the publication or in the provision of information have to be cognisant of the potential for contempt of court. Individuals or industry organisations acting on their own are bound to be concerned at falling foul of legal constraints. However, these are not insurmountable and carefully considered actions by reputable industry bodies, such as the

\begin{tabular}{lcl}
\hline Incident & Year of incident & \multicolumn{2}{c}{ Year of report publication } \\
\hline Abbeystead explosion & 1984 & 1985 (HSE, 1985) \\
Ashford building collapse & 1995 & 1999 (HSE, 1999) \\
Ramsgate walkway collapse & 1994 & 1998 (paper in the Structural Engineer (Chapman, 1998)) 1999 (Marks, 1999) \\
Heathrow tunnel collapse & 1994 & 2000 (HSE, 2000) \\
\hline
\end{tabular}

${ }^{a}$ This was in the form of a maritime structures advisory guide (i.e. general guidance rather than a specific report on Ramsgate).

Table 3. Formal publications on UK construction failures 
standing committee on structural safety, the institutions, perhaps a specially constituted body for this purpose, or the HSE itself, should not be discounted. As will be seen later, HSE already has powers to do this, and other industries have investigative bodies with statutory backing.

There is another view of legal matters that can be taken. In recent times the legislative pressure on directors and organisations to 'get it right' has increased significantly. The Health and Safety (Offences) Act 2008 (2008) raised the threshold of fines and the spread of offences for which a custodial sentence was applicable. More notably, however, and specifically so for directors, is the Corporate Manslaughter and Corporate Homicide Act 2007 (2007), which, although directed at the corporate body, has resulted in an apparent policy of parallel prosecution of gross-negligence manslaughter charges. Overall this means that it is essential for those directing organisations to know of what has adversely affected others, in a timeous manner, such that these lessons may be taken on board by themselves.

\section{Facilitating information exchange}

The hoped-for action, in cases where there is information worthy of wider dissemination, is for the organisations involved to utilise the confidential reporting on structural safety scheme (Structural-Safety, 2014a), sponsored by the Institutions of Civil and Structural Engineers and the HSE. Operational since 1995, it allows important data to become available, while maintaining confidentiality. However, the scheme has no authority to mandate contributions or to investigate matters itself. Although the reporting scheme has built up an impressive database of reports over the 9 years of operation, and deserves wider recognition and use, it still struggles to obtain contributions commensurate with the number of issues. There have been a few commendable examples of contribution from organisations waiving anonymity in the interests of industry as a whole (Structural-Safety, 2014b).

Underlying all of the above is an historical cultural reluctance, within mainstream construction at least, to share information on failures. It is shown below that not all UK industries adopt this approach, but, with few exceptions, it dogs the construction industry. An exemplary example, albeit relating to a serviceability issue, where information was made available, was the Millennium footbridge over the River Thames, which on initial opening exhibited disquieting lateral displacement (Dalard, 2001). Translating data release into a common action is the key challenge.

In the UK, as in some other countries, there is formal, but limited, provision for employees to reveal information about their employers' conduct, including matters, inter alia, relating to

- someone's workplace health or safety

a criminal offence

or when the company is not obeying the law or is covering up a wrongdoing.
This is usually referred to as 'whistle-blowing' or more strictly as 'making a disclosure in the public interest'. However, despite this provision there is good reason for employees to be nervous about its use. One only need consider examples from the National Health Service to see how acting in this manner can have profound consequences upon the individual (Telegraph, 2014). In addition, 'whistle-blowing' is usually a mechanism used in an attempt to prevent an event, whereas this paper is primarily concerned with reporting after an event. However, ensuring an environment that gives those with critical information the confidence to speak out is essential.

The answer in part is for the action to lie with companies rather than with individuals, but this approach needs the support of the board and senior management. The recent trends in the prosecution of manslaughter cases, whereby directors have been charged with gross-negligence manslaughter alongside corporate charges against the organisation (as noted above), does not bode well in this regard.

\subsection{The drive for safety in construction}

The major safety summit in 2001, called by John Prescott, Deputy Prime Minister, and the Health and Safety Commission, was for many a turning point. However, despite a plethora of initiatives and targets following this summit the focus for this was mainly directed at site activities and the well-being of the site operative in particular.

This somewhat narrow emphasis has been maintained with the result that, apart from the recognition of the benefits of greater openness, the need to tackle information flow, as described in this paper, has not been substantially addressed.

\section{Practice in other UK industries}

Not all industries keep such vital information to themselves. The more responsible approaches stem from the culture of the industry, but also from specific legislation. Often these two influences derive from adverse experience on a significant scale, for example, Piper Alpha oil rig explosion in 1988, which had a profound effect upon the management of the off-shore industry. It is a fact that the construction industry tends not to have such dramatic occurrences, which is obviously a blessing from the human perspective, but means that it does not attract the same political attention despite its significant contribution to the UK's gross domestic product (GDP) and the significant savings to be made in the maintenance of our infrastructure by having comprehensive information from past events.

The off-shore industry is a good example that exhibits a positive cultural attitude, stemming from the experience of disaster. 'Step-Change' was established in 1997 (see http://www. stepchangeinsafety.net/); it has the remit 'to make the UK the safest Oil and Gas Exploration and Production province in the world. Once achieved, we intend to maintain UK as the safest place to work' and has generated an open-reporting approach.

The airline industry has two specific schemes: 
The Civil Aviation Authority (CAA) mandatory occurrence reporting scheme (CAA, 2014) has the objective

to contribute to the improvement of flight safety by ensuring that relevant information on safety is reported, collected, stored, protected and disseminated. The sole objective of occurrence reporting is the prevention of accidents and incidents and not to attribute blame or liability.

Any incident which endangers or which, if not corrected, would endanger an aircraft, its occupants or any other person is reported.

This espouses a 'just culture' in the interests of the ongoing development of flight safety. This means the CAA supports the development, within all areas of the aviation community, of a culture in which

- 'Individuals are not punished for actions, omissions or decisions taken by them that are commensurate with their experience and training but which result in a reportable event (and these individuals are protected under law)

- But where gross negligence, wilful violations and destructive acts are not tolerated'

It expects employers to act in such a manner that does not prejudice this aim.

In parallel with the above, the UK confidential human factors incident reporting programme (see www.chirp.co.uk) also reports concerns. This is an effective measure, with information rapidly disseminated to the airline industry as a whole. The way in which this scheme looks at culpability is revealing, and useful for us in construction.

The construction industry has much to learn from these aviation schemes.

There are several industries which have legislative backing to the investigation and release of post-incident information. These include the air and rail transport, and nuclear industries. In all these industries the routine for investigation, reporting and release of data is laid down and accessible to the public. The Rail Accident Investigation Board for instance 'is not a prosecuting body and it does not apportion blame or liability. Its investigations are focused solely on improving safety and breaches of legislation are dealt with by other organisations'. The construction industry would benefit from a similar facility.

Thus it is possible to see that these schemes recognise the value of the learning process and provide the framework to encourage or require those with knowledge to share this on a no-blame basis.

Contrary experiences, of poor management and consequent reluctance to reveal shortcomings, have recently been exhibited in the NHS (NHS, 2013) illustrating that information flow is highly susceptible to the culture of the workplace, at all management levels, and that pressure to meet targets can, if not handled appropriately, cause serious shortcomings in delivery of a quality product. There are many other examples. This illustrates that it is not just the formal backing to release of data that is important, but the accompanying culture.

\subsection{Non-industry-specific facilities in the UK for formal release of data}

Although not widely known, there are existing statutory provisions for the investigation and subsequent release of data. There is provision within the Health and Safety at Work etc. Act 1974 (1974) (s14) (HASWA) for the appointment of 'any person to investigate and make a special report on any matter.' Most recently, this was implemented after the Buncefield oil depot fire and explosion in 2005 (HSE, 2005), which demonstrated how such a reporting process can proceed alongside any consideration of prosecution (or civil action). This facility is not often used; in the 39 years since the Act came into force, it has been used only 15 times (HSE, 2014a). These instances all relate to the most major events, as shown in Table 2.

It is noticeable that all the 15 events were, by any yardstick, 'major' in their immediate effect (on people or location), and none, apart from Abbeystead, involved the construction industry, either in terms of design or construction. This statement is not intended to infer that all is necessarily well in the construction industry, but to confirm again that the nature of its work leads to few fatalities at any one time, or to widespread disruption (as given in the definitions quoted at the start of this paper) compared to other industries, such as rail or heavy industry, and hence its failures do not appear to qualify under current interpretations for formal review.

The HSE has a specific protocol (HSE, 2014b, 2014c) for deciding whether to classify an incident as 'major' or to instigate the provisions of s14 of HASWA. However, this involves senior decision makers and the chair of the HSE board, thus resulting in the impression, and the practice, of limiting s14 to the very significant events, as evidenced by Table 2. It appears not to lend itself to consideration of lesser events, even though these may provide valuable learning lessons to industry as a whole.

Notwithstanding, the HSE board has recently accepted the need for learning from previous incidents. It is understood that there is now a much greater acceptance of the desirability to do all that is reasonable, without prejudicing potential prosecutions, and to release data of use to others. As part of this initiative HSE has been adopting the use of 'safety alerts and notices' and has established a website to accommodate these (HSE, 2014d). An alert is defined as 'for major faults that would result in a serious or fatal injury and where immediate remedial action is required'. A notice is

usually issued to facilitate a change in procedure or it requires an action to be undertaken to improve the level of protection or instruction in a potentially dangerous situation. It must be acted upon within a 
reasonable time, if a time period is not stated. It is not as immediate as a safety alert.

Issues to date (at time of writing in May 2014) that relate to the construction industry include lift demolition, fireplace surrounds and various concerns relating to plant. However, there is none that relates to design or management processes or that covers the more recent examples given in Table 1; yet it is failures in management processes, and the persons involved, that are the major contributor to failure. This is the '3Ps' concept introduced by the standing committee on structural safety (Structural-Safety, 2005).

In March 2014 an alert was issued by Westminster City Council following a partial ceiling collapse in a London theatre; despite the fact that investigations were still in hand, this had the agreement of HSE (Structural-Safety, 2014c). This is an excellent example of a contemporary report, issued within a reasonable time of the incident, and of general interest; it shows what can be achieved.

Nonetheless, as can be seen, the HSE policy has not led to the investigation and publication of many more construction industry incidents, and there remains a significant shortfall in the availability of crucial data and a seeming reluctance on the part of HSE to expand or commit to anything further: a proposal to review the current provision, and use of s14, was removed by HSE from a report due to be presented to its construction industry advisory committee by a working group considering catastrophic events (HSE, 2013).

There are a few examples of construction industry related failures in the past, which have led to information availability. These are shown in Table 3. However, these examples again illustrate the time lapse between incident and availability of information; 4 years is common. It is questioned whether other factors are at work here, as the time lapse for Abbeystead was only 1 year. It is notable that the last such report was 14 years ago.

\section{Practice in some other countries}

This concern is not confined to the UK alone, but it is noticeable that practice in some other countries allows more rapid publication of contributory causes of failure as can be seen from Table 4 . Although the background legislative provision varies between the five countries exampled in Table 4, the result was the same: a valuable factual publication, available within 12 months or so of the incident, giving a comprehensive analysis which, even if not complete, was sufficient to determine the needs for procedural or material changes, or at least alert practitioners to a concern.

As an example of provisions in other countries, in the USA the National Institute of Standards and Technology is authorised under federal law to investigate major building failures. The aim is to

provide for the establishment of investigative teams to assess building performance and emergency response and evacuation procedures in the wake of any building failure that has resulted in substantial loss of life or that posed the potential for substantial loss of life.

The goal is to recommend improvements to the way in which buildings are designed, constructed, maintained and used. The institute has responsibility to dispatch teams of experts, where appropriate and practical, within 48 hours after major building disasters. The law gives the teams a clear mandate to

n 'establish the likely technical cause of building failures'

- 'evaluate the technical aspects of procedures used for evacuation and emergency response'

- 'recommend specific changes to building codes, standards, and practices'

- 'recommend any research or other appropriate actions needed to improve the structural safety of buildings; and/or changes in emergency response and evacuation procedures'

- 'make final recommendations within 90 days of completing an investigation.’ (NIST, 2014)

The governing act covers items such as access, inspection and testing, and relationship to other bodies should a criminal act be suspected. Importantly, outputs cannot be used in a court of law.

In a similar vein, the Dutch Safety Board (see http://www. onderzoeksraad.nl/en/) also has legal backing to investigate incidents; in this case an incident is not only defined to include disasters and accidents but also 'incidents that could have turned
Collapse of a highway bridge span onto the road below Partial collapse of a complex building

Nicoll Highway, Singapore

FC Twente stadium,

Netherlands

I-35W, USA

of incident publication

Collapse of a major temporary works structure for an open excavation

Partial collapse of a grandstand structure during construction

Total collapse of an existing highway bridge in Minneapolis
2006

2004

2004

2011

2007
2007

Table 4. Other countries - publication of causes of failure 
out badly' (see http://www.onderzoeksraad.nl/uploads/fm/ planatory-atcment_urgdom_Act_ihn_Safety-rark.pdf). As for the USA, outputs of the board cannot be used in legal proceedings.

\section{Summary}

This paper has set out to demonstrate the need for a greater degree of reporting on industry failures on the basis that even failures that are not 'major' provide valuable learning lessons. The current systems are biased towards the significantly 'major' incidents and thus exclude many learning opportunities.

A number of issues require consideration in the determination of whether an incident is worthwhile investigating with a view to disseminating the lessons to industry, as described below.

Serious incidents: the definition should be expanded to allow inclusion of incidents which are not necessarily 'major' in scope or risk immediate fatalities. Many smaller cases present pertinent reminders of risk, of the need for robust procedures and of day-today lessons.

Transferable lessons: the construction industry is in reality an amalgam of many disparate industries, not all of which would consider themselves to be 'construction' - for example, process engineering. Nonetheless, many lessons from incidents are transferrable. They hold good in all circumstances and thus deserve a wider audience.

Encouraging the release of critical information which is part of a civil investigation is in many ways a harder proposition than that for criminal cases, as the parties in control are individual clients, insurance companies, brokers, or those other parties directly involved in the action. There is no overarching body with the authority to insist or organise the release. Nonetheless, there are some options worthy of consideration and further review; these are listed below.

(a) Review the duty on expert witnesses under safety legislation, or under their code of conduct stemming from professional membership of industry institutions, to reveal safety-critical data for the wider industry good.

(b) Instigate a limitation to the period during which parties may prevent disclosure (only a partial solution, as this would still create delay).

For situations where there is a criminal investigation, action is needed to

(a) review the current statutory provisions under the Health and Safety at Work etc. Act, and those for specific industries

(b) encourage a review of HSE's interpretation of 'serious incident', and the associated protocols to allow greater use of existing facilities

(c) consider how the best of foreign practice might be incorporated into UK procedure.
These actions require, for best effect, the involvement and support of HSE, insurers, industry (not only construction, but other industries with an established culture in this field) and professional institutions. This is considered sufficiently important to convene a specific committee to consider these, and related issues, such as that set up under the chairmanship of Lord Penney (Penney, 1974).

The underlying need is to change the attitude from one of a protective reluctance to divulge, to one of openness, as has been achieved elsewhere. However, this will only come about with the appropriate culture, leadership and protection.

\section{Acknowledgements}

The author would like to thank Griffiths and Armour for their time in discussing some of these issues.

\section{REFERENCES}

Burgoyne C and Scantlebury R (2008) Lessons learned from the bridge collapse in Palau. Proceedings of the Institution of Civil Engineers - Civil Engineering 161(6): 28-34.

CAA (Civil Aviation Authority) (2014) Mandatory Occurrence Reporting Scheme. CAA, West Sussex, UK, CAP 382. See http://www.caa.co.uk/default.aspx?catid=1425\&pageid $=8178$ (accessed 14/10/2014).

Chapman JC (1998) Collapse of the Ramsgate Walkway. The Structural Engineer 76(1). See http://www.istructe.org/journal/ volumes/volume-76-(published-in-1998)/issues/issue-1/articles/ collapse-of-the-ramsgate-walkway (accessed 14/10/2014).

Construction Enquirer (2012) Five-storey steel frame building collapses. See http://www.constructionenquirer.com/2012/02/ 01/6m-church-under-construction-collapses-in-ilford/ (accessed $14 / 10 / 2014)$.

Corporate Manslaughter and Corporate Homicide Act 2007 (2007) Elizabeth II. Chapter 19. Her Majesty's Stationery Office, London, UK.

Dalard P, Fitzpatrick AJ, Flint A et al. (2001) The London Millennium footbridge. The Structural Engineer 79(22): 17-33.

Donnelly L (2014) Top nurse warns on NHS whistleblowers. The Telegraph, 11 May.

Health and Safety at Work etc. Act 1974 (1974) Elizabeth II. Chapter 37. Her Majesty's Stationery Office, London, UK.

Health and Safety (Offences) Act 2008 (2008) Elizabeth II. Chapter 20. Her Majesty's Stationery Office, London, UK.

HMG (Her Majesty's Government) (1995) The Reporting of Injuries, Diseases and Dangerous Occurrences Regulations 1995 (RIDDOR). The Stationery Office, London, UK. Statutory Instrument 1995, No. 3163.

HSE (Health and Safety Executive) (1985) The Abbeystead Explosion: A Report of the Investigation by the Health and Safety Executive into the Explosion on 23 May 1984 at the Valve House of the Lune/Wyre Water Transfer Scheme at Abbeystead. HSE, UK.

HSE (1999) Report into the Collapse of a Three-Storey Building at Woodthorpe Road, Ashford, Middlesex (Incident report). HSE, UK. 
HSE (2000) The Collapse of NATM Tunnels at Heathrow Airport. HSE, UK.

HSE (2005) Buncefield Response: Reports and Recommendations Arising from the Competent Authority's Response to the Buncefield Incident. HSE, Bootle, UK. See http://www.hse.gov. uk/comah/buncefield/response.htm (accessed 14/10/2014).

HSE (2011) RR834 - Preventing Catastrophic Events in Construction. HSE, Bootle, UK. See http://www.hse.gov.uk/ research/rrhtm/rr834.htm (accessed 14/10/2014).

HSE (2013) Managing Risks with Catastrophic Potential - Report on the Work of CONIAC's Catastrophic Events Working Group. Construction Industry Advisory Committee, Bootle, UK, paper M3/2013/1. See http://www.hse.gov.uk/aboutus/meetings/ iacs/coniac/201113/coniac-paper-201113.pdf (accessed 14/10/ 2014).

HSE (2014a) Major Incident Introduction. HSE, Bootle, UK, major incident procedure. See http://www.hse.gov.uk/foi/internalops/ og/ogprocedures/majorincident/index.htm (accessed 14/10/ 2014).

HSE (2014b) Freedom of Information (FOI) request, April (2014). HSE (2014c) Major Incident Response and Investigation \& Major Incident Policy and Procedure Review. HSE, Bootle, UK. See http://www.hse.gov.uk/enforce/mirai.pdf (accessed 14/10/ 2014).

HSE (2014d) Health and Safety Bulletins. HSE, Bootle, UK. See http://www.hse.gov.uk/safetybulletins/index.htm (accessed 14/ 10/2014).

Marks RJE (1999) Safety in Ports - Ship-to-Shore Linkspans and Walkways. A Guide to Procurement, Operation and Maintenance. Ciria, London, UK, C518.
NHS (National Health Service) (2013) The Mid Staffordshire NHS Foundation Trust Public Inquiry. See http://www. midstaffspublicinquiry.com/ (accessed 14/10/2014).

NIST (National Institute of Standards and Technology) (2014). http://nist.gov/public_affairs/releases/n02-19.cfm (accessed 14/ 11/2014).

Penney W (1974) Lord Penney: Report of the Interim Committee on Structural Safety. Institution of Structural Engineers, London, UK.

RAIB (Rail Accident Investigation Branch) (2014) http://raib.gov.uk/ about_us/index.cfm (accessed 11/1/2014).

Royal Commission (1971) Report of Royal Commission into the Failure of West Gate Bridge. Royal Commission, Victoria, Australia, see http://prov.vic.gov.au/wp-content/uploads/2012/ 02/VPARL1971-72No21.pdf (accessed 14/10/2014).

Structural-Safety (2005) Standing Committee on Structural Safety 15th Biennial Report. See http://www.structural-safety.org/ media/41903/L18_scoss-BIENNIAL_REPORT_NO_15.copy. pdf (accessed 17/11/2014).

Structural-Safety (2014a) Confidential Reporting. StructuralSafety, CROSS, Wirral, UK, see http://www.structural-safety. org/confidential-reporting/ (accessed 14/10/2014).

Structural-Safety (2014b) Counterweight Failure - Plank Lane Bridge. Structural-Safety, CROSS, Wirral, UK, report ID 47, see http://www.structural-safety.org/publications/view-report/? report=3010 (accessed 14/10/2014).

Structural-Safety (2014c) Newsletter 34. Structural-Safety, CROSS, Wirral, UK, Item 442. See http://www.structural-safety. org/publications/view-newsletter/?newsletter=4369 (accessed 14/10/2014).
WHAT DO YOU THINK?

To discuss this paper, please submit up to 500 words to the editor at journals@ice.org.uk. Your contribution will be forwarded to the author(s) for a reply and, if considered appropriate by the editorial panel, will be published as a discussion in a future issue of the journal.

Proceedings journals rely entirely on contributions sent in by civil engineering professionals, academics and students. Papers should be 2000-5000 words long (briefing papers should be 1000-2000 words long), with adequate illustrations and references. You can submit your paper online via www.icevirtuallibrary.com/content/journals, where you will also find detailed author guidelines. 